Original article

\title{
Gender based Differences in COVID-19 patients
}

Sami Ullah Mumtaz ${ }^{1 *}$, Somia Iqtadar ${ }^{1}$, Sajid Abaidullah¹, Khalid Masood Gondal ${ }^{2}$, Amber Hassan ${ }^{3}$, Asad Aslam Khan 4 and Javed Akram ${ }^{5,6}$

${ }^{1}$ Department of Medicine, King Edward Medical University/Mayo Hospital Lahore, Pakistan

${ }^{2}$ Department of Surgery, King Edward Medical University/Mayo Hospital, Lahore, Pakistan

${ }^{3}$ Faculty of Allied Health Sciences, The University of Lahore, Pakistan

${ }^{4}$ Department of Ophthalmology,King Edward Medical University/ Mayo Hospital, Lahore, Pakistan

${ }^{5}$ Department of Physiology and Cell Biology, University of Health Sciences, Lahore, Pakistan

${ }^{6}$ Institute for Regenerative Medicine, University of Health Sciences, Lahore, Pakistan

* drsumumtaz@gmail.com

\section{Abstract:}

Coronaviruses are a huge family of viruses that originate disease extending from the common cold to further fatal maladies. Objective: The study was conducted to determine the gender based differences in COVID-19 patients. Methods: Study included total 150 participants visiting Department of Medicine, Mayo Hospital, Lahore, Pakistan. Data were collected through self-structured questionnaire using non-probability convenient sampling. Prior written informed consents were taken from the participants. Ethical approval was taken from The University of Lahore, Lahore. Data were analyzed through SPSS version 25.0. Results: Results showed that among the comorbidities hypertension was most common in COVID-19 patients followed by diabetes mellitus, especially in females. Whereas renal disorders and asthma were most reported in males. Analysis revealed that there was a significant association $(p=0.001)$ between disease severity and gender. Conclusion: Study concluded that there was significant association between gender and disease severity.

Key words: COVID-19, gender based differences, comorbidities

\section{Introduction:}

Coronavirus disease 2019 (COVID-19), triggered by a novel enclosed RNA betacoronavirus entitled severe acute respiratory syndrome coronavirus 2 (SARS-CoV-2) has turned into a community health emergency of worldwide apprehension [1]. The expressions of COVID-19 route the spectrum from asymptomatic illness to severe acute respiratory contamination [2-5], and the renowned human-to-human spread remarkable accelerating the hazard of considerably extensive transmission of the infection [6-8]. The extraordinary transience results from fulminant pneumonia causing to sudden respiratory distress syndrome and manifold organ disaster $[9,10]$. Initial literature propose that comorbidities results a further severe progression of infection and a lesser diagnosis $[11,12]$. Conferring to the Asian clinical trials, the most predominant symptoms comprise of cough, sputum production, fever, myalgia, irregular heartbeat, dyspnea, headache, diarrhea, and painful throat $[13,14]$.

Current literature has reported the greater threats of inferior clinical consequences in patients diseased with avian influenza [15-17], severe acute respiratory syndrome coronavirus (SARS-CoV) [18], and has revealed that comorbidities together with diabetes mellitus (DM), cardiovascular disease (CVD), hypertension, chronic respiratory diseases, chronic kidney disease (CKD), and malignancy are considerably linked with a unfortunate diagnosis or even demise. A less number of clinical hazard aspects for a poor diagnosis 
linked with COVID-19 have also been stated, comprising masculinity, elder age, and the existence of comorbidities $[19,20]$, with hypertension being the utmost common, afterwards DM and CVD [21, 22]. Assumed the practically irresistible worldwide development of SARS-CoV-2, accompanied by the high occurrence of comorbidities globally, the combination of these two conditions will stand inordinate clinical, societal, and financial drains to mankind [23].

In the ongoing pandemic situation, clinical trials on COVID-19 are of the most major concerns for the scientists worldwide. Current study was carried out to determine the gender based differences among COVID patients.

\section{Methods:}

Study included total 150 participants visiting Department of Medicine, Mayo Hospital, Lahore,
Pakistan. Data were collected through selfstructured questionnaire using non-probability convenient sampling. Prior written informed consents were taken from the participants. Ethical approval was taken from The University of Lahore, Lahore. Data were analyzed through SPSS version 25.0. p-value less than 0.05 was considered significant.

\section{Results:}

Results showed that among the comorbidities hypertension was most common in COVID-19 patients followed by diabetes mellitus, especially in females. Whereas renal disorders and asthma were most reported in males (4 and 3 respectively). Cardiac myopathy and COPD were equally reported in both genders, Figure 1.

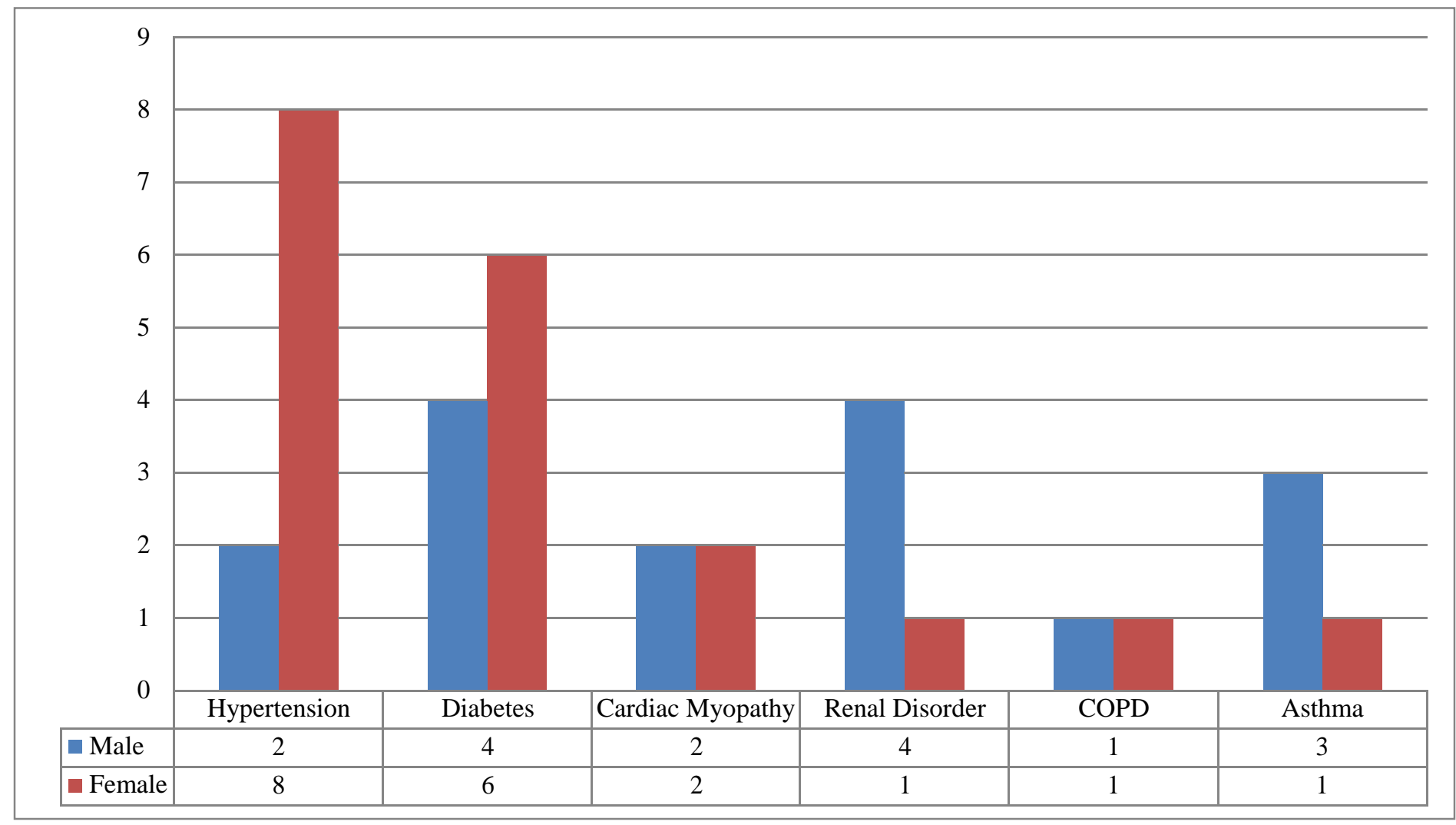

Figure 1: Comorbidities According to Gender

According to results 8 males were asymptomatic whereas only 1 female was asymptomatic, 38 males were having mild symptoms but only 22 females were having mild symptoms. On contrary 31 males were having moderate symptoms and 53 females were having moderate symptoms, Figure 2. 


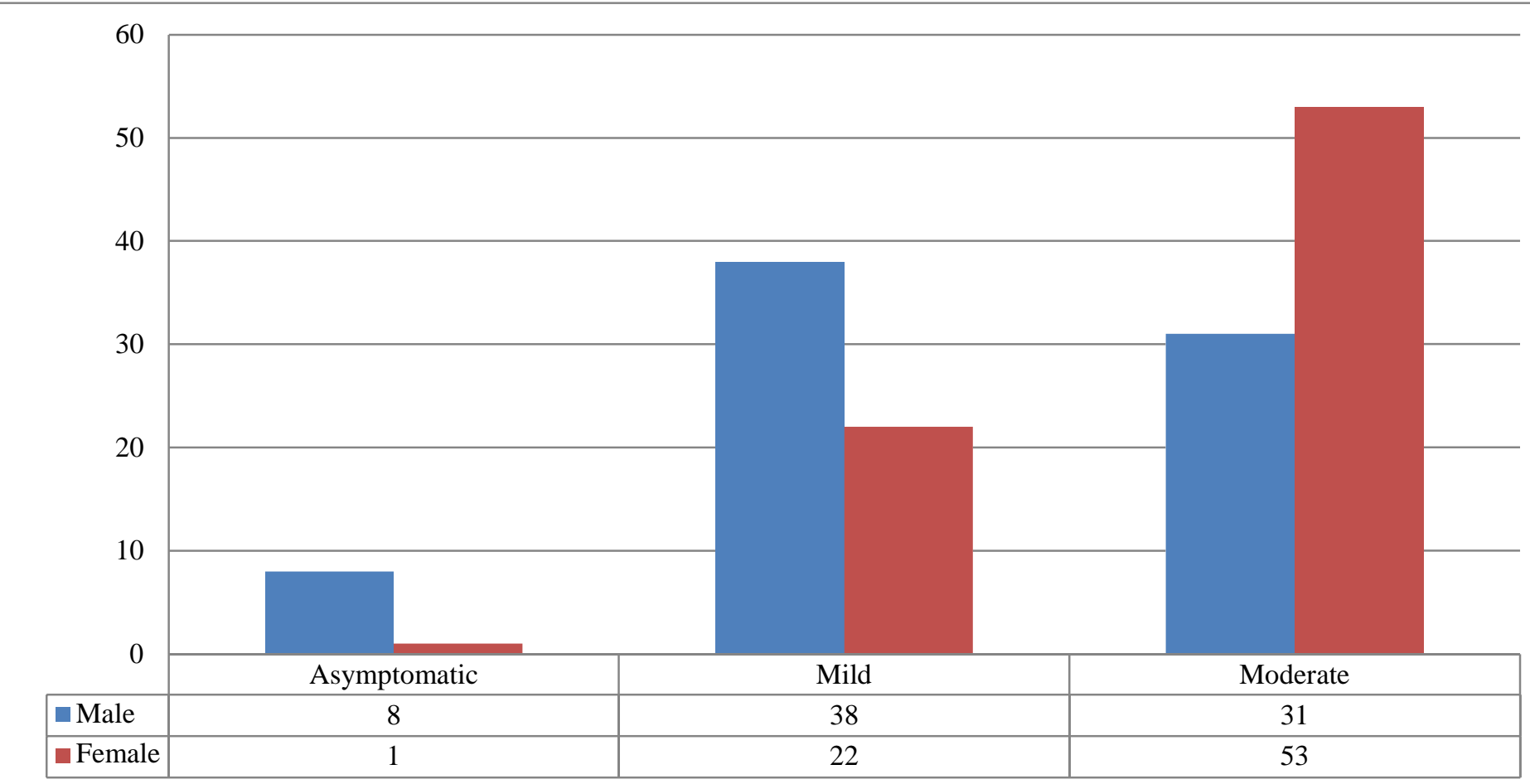

Figure 2: Disease Severity According to Gender

Analysis revealed that there was a significant association $(p=0.001)$ between disease severity and gender, Table 1.

\begin{tabular}{|l|c|c|c|c|c|}
\hline \multirow{2}{*}{ Gender } & \multicolumn{4}{|c|}{ Disease Severity } & P-value \\
\cline { 2 - 5 } & Asymptomatic & Mild & Moderate & Total & \\
\cline { 1 - 5 } Male & 8 & 38 & 31 & 77 & \multirow{2}{*}{0.001} \\
\cline { 1 - 4 } Female & 1 & 22 & 53 & 76 & \\
\cline { 1 - 5 } Total & 9 & 60 & 84 & 153 & \\
\hline
\end{tabular}

Table 1: Association between Disease Severity and Gender

\section{Discussion:}

Findings of current study revealed that hypertension, diabetes, renal disorder, cardiac myopathy, asthma and COPD were the reported comorbidities among the study participants. Similar findings were reported by Zohu et al., that hypertension, diabetes, cardiovascular disease, respiratory disease, kidney disease, are clinical risk factors for a severe or lethal consequence linked with COVID-19 [24]. But on contrary the meta-analyses conducted by Yang et al., and Li et al., indicated no noteworthy corelation between diabetes mellitus and the severe consequences linked with COVID-19 [25]. Moreover, the analysis by Wang et al. reported no association between CKD, and the worsening of illness in COVID-19 patients [26].

\section{Conclusion:}

Study concluded that that hypertension, diabetes, renal disorder, cardiac myopathy, asthma and COPD were the reported comorbidities among the study participants. 
Also that there was significant association between gender and disease severity.

\section{References:}

1. Lu R, Zhao X, Li J, Niu P, Yang B, Wu H, Wang W, Song H, Huang B, Zhu N, Bi Y, (2020). Genomic characterisation and epidemiology of 2019 novel coronavirus: implications for virus origins and receptor binding. The lancet. 395(10224):565-74.

2. Chen N, Zhou M, Dong X, Qu J, Gong F, Han Y, Qiu Y, Wang J, Liu Y, Wei Y, Yu T, (2020). Epidemiological and clinical characteristics of 99 cases of 2019 novel coronavirus pneumonia in Wuhan, China: a descriptive study. The lancet. 395(10223):507-13.

3. Deng SQ, Peng HJ, (2020). Characteristics of and public health responses to the coronavirus disease 2019 outbreak in China. Journal of clinical medicine, $\mathbf{9}(2): 575$.

4. Huang $C$, Wang $Y$, Li X, Ren L, Zhao J, Hu Y, Zhang L, Fan G, Xu J, Gu X, Cheng Z, (2020). Clinical features of patients infected with 2019 novel coronavirus in Wuhan, China. The lancet, 395(10223):497-506.

5. Wang B, Li R, Lu Z, Huang Y, (2020). Does comorbidity increase the risk of patients with COVID-19: evidence from metaanalysis. Aging (Albany NY). 12(7):6049.

6. Li B, Yang J, Zhao F, Zhi L, Wang X, Liu L, Bi Z, Zhao Y, (2020). Prevalence and impact of cardiovascular metabolic diseases on COVID-19 in China. Clinical Research in Cardiology. 109(5):531-8.

7. Phan LT, Nguyen TV, Luong QC, Nguyen TV, Nguyen HT, Le HQ, Nguyen TT, Cao TM, Pham QD, (2020). Importation and human-to-human transmission of a novel coronavirus in Vietnam. New England Journal of Medicine. 382(9):872-4.

8. Rothe C, Schunk M, Sothmann P, Bretzel G, Froeschl G, Wallrauch C, Zimmer T, Thiel V, Janke C, Guggemos W, Seilmaier
M, (2020). Transmission of 2019-nCoV infection from an asymptomatic contact in Germany. New England journal of medicine. 382(10):970-1.

9. Wu Z, McGoogan JM, (2020). Characteristics of and important lessons from the coronavirus disease 2019 (COVID-19) outbreak in China: summary of a report of 72314 cases from the Chinese Center for Disease Control and Prevention. Jama. 323(13):1239-42.

10. Arentz M, Yim E, Klaff L, Lokhandwala S, Riedo FX, Chong M, Lee M, (2020). Characteristics and outcomes of 21 critically ill patients with COVID-19 in Washington State. Jama. 323(16):1612-4.

11. Chen $R$, Liang W, Jiang $M$, Guan W, Zhan C, Wang T, Tang C, Sang L, Liu J, Ni Z, Hu $Y,(2020)$. Risk factors of fatal outcome in hospitalized subjects with coronavirus disease 2019 from a nationwide analysis in China. Chest. 158(1):97-105.

12. Guan WJ, Ni ZY, Hu Y, Liang WH, Ou CQ, He JX, Liu L, Shan H, Lei CL, Hui DS, Du B, (2020). Clinical characteristics of coronavirus disease 2019 in China. New England journal of medicine. 382(18):170820.

13. Young BE, Ong SW, Kalimuddin S, Low JG, Tan SY, Loh J, Ng OT, Marimuthu K, Ang LW, Mak TM, Lau SK, (2020). Epidemiologic features and clinical course of patients infected with SARSCoV-2 in Singapore. Jama. 323(15):148894.

14. Wan S, Xiang YI, Fang W, Zheng Y, Li B, Hu Y, Lang C, Huang D, Sun Q, Xiong $Y$, Huang $X,(2020)$. Clinical features and treatment of COVID-19 patients in northeast Chongqing. Journal of medical virology. 92(7):797-806.

15. Martínez A, Soldevila N, Romero-Tamarit A, Torner N, Godoy $P$, Rius C, Jané $M$, Domínguez $\dot{A}$, Surveillance of Hospitalized Cases of Severe Influenza in Catalonia Working Group, (2019). Risk 
factors associated with severe outcomes in adult hospitalized patients according to influenza type and subtype. PLoS One. 14(1):e0210353.

16. Mauskopf J, Klesse M, Lee S, HerreraTaracena G, (2013). The burden of influenza complications in different highrisk groups: a targeted literature review. Journal of medical economics. 16(2):26477.

17. Placzek HE, Madoff LC, (2014). Association of age and comorbidity on 2009 influenza A pandemic H1N1-related intensive care unit stay in Massachusetts. American journal of public health. 104(11):e118-25.

18. Booth CM, Matukas LM, Tomlinson GA, Rachlis AR, Rose DB, Dwosh HA, Walmsley SL, Mazzulli T, Avendano M, Derkach P, Ephtimios IE, (2003). Clinical features and short-term outcomes of 144 patients with SARS in the greater Toronto area. Jama. 289(21):2801-9.

19. Deng SQ, Peng HJ, (2020). Characteristics of and public health responses to the coronavirus disease 2019 outbreak in China. Journal of clinical medicine. 9(2):575.

20. Yang F, Shi S, Zhu J, Shi J, Dai K, Chen X, (2020). Analysis of 92 deceased patients with COVID-19. Journal of medical virology. 92(11):2511-5.

21. Huang C, Wang $Y$, Li X, Ren L, Zhao J, Hu Y, Zhang L, Fan G, Xu J, Gu X, Cheng Z, (2020). Clinical features of patients infected with 2019 novel coronavirus in Wuhan, China. The lancet. 395(10223):497-506.

22. Wang D, Hu B, Hu C, Zhu F, Liu X, Zhang J, Wang $B$, Xiang $H$, Cheng $Z$, Xiong $Y$, Zhao $Y,(2020)$. Clinical characteristics of 138 hospitalized patients with 2019 novel coronavirus-infected pneumonia in Wuhan, China. Jama. 323(11):1061-9.

23. Emanuel EJ, Persad G, Upshur R, Thome B, Parker M, Glickman A, Zhang C, Boyle
C, Smith M, Phillips JP, (2020). Fair allocation of scarce medical resources in the time of Covid-19. N Engl J Med. 382: 2049-55.

24. Zhou Y, Yang Q, Chi J, Dong B, Lv W, Shen L, Wang Y, (2020). Comorbidities and the risk of severe or fatal outcomes associated with coronavirus disease 2019: A systematic review and metaanalysis. International Journal of Infectious Diseases. 99:47-56

25. Yang $X, Y u Y, X u J$, Shu $H$, Liu H, Wu $Y$, Zhang L, Yu Z, Fang M, Yu T, Wang Y, (2020). Clinical course and outcomes of critically ill patients with SARS-CoV-2 pneumonia in Wuhan, China: a singlecentered, retrospective, observational study. The Lancet Respiratory Medicine. 8(5):475-81.

26. Wang $F$, Wang $H$, Fan J, Zhang $Y$, Wang $H$, Zhao Q, (2020). Pancreatic injury patterns in patients with coronavirus disease 19 pneumonia. Gastroenterology. 159(1):36770. 